\title{
INVESTIGATIONS ON THE INFLUENCE OF ISOTROPY IMPROVING ALLOY ADDITIVES WHEN MACHINING 38MNSIVS6
}

\author{
T. Bergs ${ }^{1}$, T. Seelbach ${ }^{1 *}$, D. Schraknepper ${ }^{1}$ \\ ${ }^{1}$ Laboratory of Machine Tools and Production Engineering (WZL) of RWTH Aachen University, Aachen, Germany \\ ${ }^{*}$ Corresponding author; e-mail: t.seelbach@wzl.rwth-aachen.de
}

\begin{abstract}
Resulfurized steels are commonly used in the industry due to its good machinability, which can be related to the formation of microstructural manganese sulfide (MnS) inclusions. On the downside, MnS inclusions cause a high steel anisotropy due to its elongated form. Within this paper, the effect of a MnS reduction and the influence of different countermeasures on the machinability is investigated. The addition of either selenium $(\mathrm{Se})$ or bismuth $(\mathrm{Bi})$ is combined with a reduction of the sulfur content with the aim to increase the isotropy and, consequently, the fatigue performance of the steel variants. Drilling investigations in longitudinal and transversal direction to the steel fiber are conducted and evaluated regarding wear development and cutting forces. The experiments showed that the addition of the two elements resulted in a good compensation of the MnS reduction regarding the machinability.
\end{abstract}

\section{Keywords:}

Micro-alloyed steel; Isotropy; Machinability; Inclusions

\section{INTRODUCTION}

The reduction of the vehicle weight has been demonstrated as a promising factor to enable immediate $\mathrm{CO}_{2}$ and $\mathrm{NOx}$ reduction. Considering the automotive parts, the powertrain components, especially the crankshaft, are considered as the most adequate parts to be downsized [Raedt 2014, Pawar 2015]. In the crankshaft manufacturing the machining costs represent more than $50 \%$ of the total manufacturing costs [Montazersadgh 2007]. The most commonly used steels for crankshafts are quenched and tempered steels for large high-power engines as well as micro-alloyed ferritic-perlitic (F-P) steels. Micro-alloyed F-P steels contain low amounts of alloying elements, e.g. vanadium, titanium or niobium, to form micro-precipitates to reach desired mechanical properties without heat treatment [Pichard 1993]. The most common grade is 38MnSiVS6, which represents the reference material underlying this work. The alloy element sulfur is commonly used to enhance the machinability. This is due to the formation of elongated manganese sulfides (MnS) inclusions. However, MnS inclusions cause a high steel anisotropy, which negatively affects the crankshaft fatigue performance. The first approach to enable downsizing of the crankshaft is the improvement of the steel isotropy. Within this paper, the effect of a MnS reduction and the influence of different countermeasures on the machinability are investigated. By adding selenium, the morphology of the MnS inclusion is modified to enhance the isotropy. The addition of bismuth is a promising approach to compensate the decrease in machinability caused by the sulfur reduction. Furthermore, the effects of those countermeasures on the machinability are investigated by analyzing the wear mechanisms and the thermo-mechanical load on the cutting tool in drilling. A second approach to enable a crankshaft downsizing is the improvement of fatigue performance by increasing the steel strength. A newly developed ferritic-perlitic micro-alloyed steel grade is integrated into the cutting tests and is investigated with regard to its machinability. Fundamental cutting tests are conducted to enable a comparison of the developed steel variants to the industrial standards.

\section{EXPERIMENTAL INVESTIGATIONS}

This chapter is divided into two parts. First, the different workpiece material variants are presented and the characteristics of each alloy element are explained. The second part describes the experimental setup for the machining tests.

\subsection{Workpiece Material}

Within this study, six different steel grades are investigated, the reference material 38MnSivS6 and five newly developed steels, which were developed and manufactured by SIDENOR. Within the first approach, countermeasures to improve the isotropy are investigated regarding the influence on the machinability. The second approach deals with an increase of the steel strength to enable a downsizing of automotive parts. The steels variants for both approaches are presented in the following section.

\section{Approach 1: Steels with improved isotropy}

Given that the MnS notably decrease the steel isotropy, the most direct way to improve this is the reduction of the sulfur (S) content. Therefore, a variant with low $S$ content is considered in the investigations (38LS). Nevertheless, this $S$ reduction has been proved to decrease the steel machinability. For compensating this drop, two steel variants with either the alloying element selenium (38Se) or bismuth $(38 \mathrm{Bi})$ are considered in the investigations. Adding the element Se results in a modification of the inclusion 
morphology. The originally elongated form of the MnS inclusions change to a more globular shape, which suggest that the machinability becomes more uniform in both directions. The negative effect of elongated inclusions on the transversal mechanical properties of the steel is reduced and the isotropy improves. The change of the morphology is due to a reduction of MnS hot formability as well as the formation of manganese selenides (MnS-Se), which reduce the amount of MnS inclusions [Essel 2006]. The addition of bismuth does not affect the inclusion's morphology, but it improves the machinability by forming a lubrication film in the cutting zone due to its low melting point $\left(271^{\circ} \mathrm{C}\right)$ and, consequently, lowering the cutting forces and improving the chip breakage [Essel 2006]. Furthermore, the addition of bismuth results in a reduction of the wear development because it acts as a diffusion barrier. The element bismuth behaves in a similar way as lead, except for its non-toxicity, which limits the amount of allowed lead content in steels [ECSC 2004].

\section{Approach 2: High strength steels}

A second approach to enhance the fatigue performance is to increase the ultimate tensile strength (UTS). Therefore, two variants of the high strength F-P micro-alloyed stee grade $43 \mathrm{MnSiV} 6$ are considered in the investigations. The first one contains a low $S$ content to maximize the fatigue limit (43LS), the second one contains additional bismuth $(43 \mathrm{Bi})$ to improve the machinability as it was outlined for Approach 1. All in all, six different steels grades were investigated regarding their machinability. In Tab. 2 the chemical composition of each steel is shown. Fig. 1 shows the micro-sections of the investigated materials.
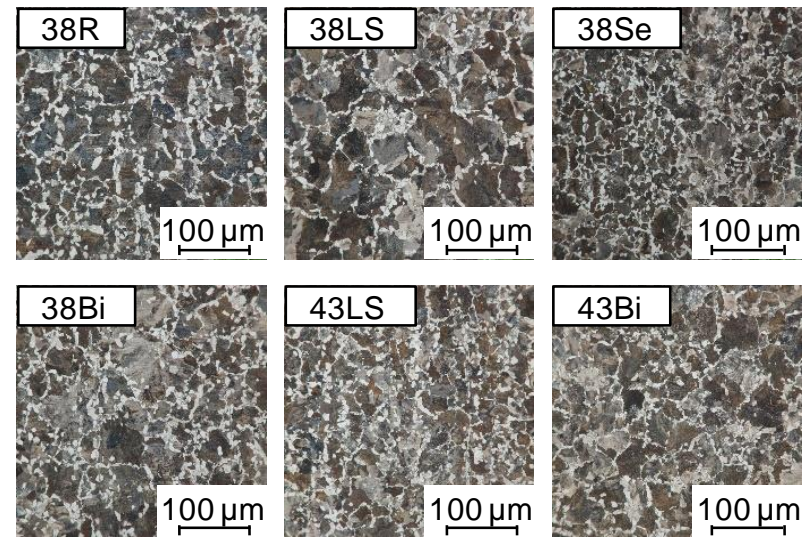

Fig. 1: Microstructure of all investigated steel variants.

In Fig. 1 it can be seen, that all different steel variants obtain a $100 \%$ ferrite-pearlite (FP) microstructure. The four variants of $38 \mathrm{MnSiV} 6$ showed a very similar FP distribution. The amount of pearlite was lower in comparison to the $43 \mathrm{MnSiV} 6$ variants due to the lower carbon content. The amount of manganese was kept below $1.50 \%$ to avoid the formation of bainite, which would have caused a drop in the machinability compared to F-P steels. Additionally, analyzing the effect of the selenium addition showed, that most of the MnS inclusions have been successfully transformed into MnS-Se.

\subsection{Experimental Setup}

The standard drilling experiments were performed in longitudinal and transversal direction with respect to the steel fiber due to the different mechanical and microstructural properties in each direction. The test setup is depicted in Fig. 2. For measuring the cutting forces during drilling, the rotating force dynamometer (RCD) Kistler 9125 was used for the transversal tests, while the static force measurement platform Kistler 9272 was used for the longitudinal tests. The experiments were conducted on the machining center Ex-Cell-O XHC 241.
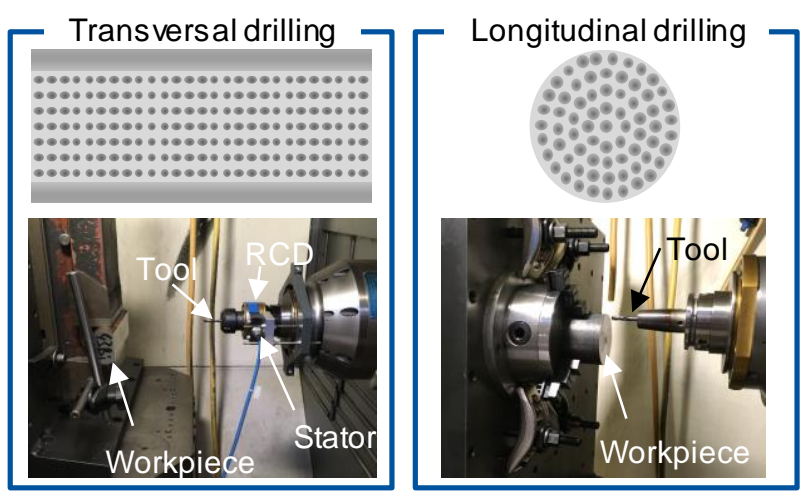

Fig. 2: Experimental setup for longitudinal and transversal drilling.

The cutting parameters for the underlying machining tests were chosen according to those used in the industrial crankshaft manufacturing. This is to guarantee the obtaining of representative results. Therefore, the stroke $l_{e}$, the feed rate $f$, the cutting speed $v_{c}$, the tool geometry as well as the cooling/lubrication strategy from the industry were applied. As lubrication, minimum quantity lubrication (MQL) was applied through the spindle. The test procedure and cutting parameters are summarized in Tab. 1.

Tab. 1: Parameters for the underlying cutting tests.

\begin{tabular}{lc}
\hline Process & Drilling \\
Machine tool & Ex-Cell-O XHC 241 \\
Tool supplier & Gühring \\
Tool Type & RT $100 \mathrm{U}$ \\
Coating & Nano-FireX (PVD TiN-TiAIN) \\
Stroke le & $15.5 \mathrm{~mm}$ \\
Diameter $\mathrm{d}$ & $5 \mathrm{~mm}$ \\
Feed $\mathrm{f}$ & $0.16 \mathrm{~mm}$ \\
Cutting speed $\mathrm{v}_{\mathrm{c}}$ & $70 \mathrm{~m} / \mathrm{min}$ \\
Lubrication & $\mathrm{MQL}$ (Rother Aerosol Mater \\
& Lubricant c-st) \\
\hline
\end{tabular}

\section{RESULTS}

The following chapter is divided into two parts. First, the results regarding the wear development and wear mechanisms are presented. Then, the results of the cutting force measurements are shown and discussed. 
Tab. 2: Chemical composition of all steel variants (provided by SIDENOR).

\begin{tabular}{cccccccccc}
\hline Variant & $\mathrm{C}$ & $\mathrm{Mn}$ & $\mathrm{Si}$ & $\mathrm{S}$ & $\mathrm{V}$ & $\mathrm{Al}$ & $\mathrm{Se}$ & $\mathrm{Bi}$ \\
\hline 38R & 0,36 & 1,33 & 0,59 & 0,089 & 0,1 & 0,016 & 0,001 & 0,00 \\
38LS & 0,37 & 1,43 & 0,65 & 0,025 & 0,09 & 0,012 & 0,001 & 0,00 & 0,00 \\
38Se & 0,39 & 1,50 & 0,62 & 0,056 & 0,11 & 0,010 & 0,028 & $0,04-0,05$ \\
38Bi & 0,38 & 1,36 & 0,61 & 0,063 & 0,11 & 0,013 & 0,001 & 0,013 \\
43LS & 0,46 & 1,20 & 0,92 & 0,025 & 0,25 & 0,007 & 0,001 & 0,00 \\
43Bi & 0,47 & 1,19 & 0,89 & 0,032 & 0,26 & 0,010 & 0,001 & $0,06-0,09$ \\
\hline
\end{tabular}

\subsection{Wear Development}

Wear studies were performed for all steel variants with one repetition each. The tool life of some variants was characterized by cutting edge chipping. For the other variants, the wear state after a defined number of drill holes was compared. Fig. 3 shows the wear development when machining the different steel variants in longitudinal direction. It can be seen that the tools, which were used for machining $38 \mathrm{R}$ and $38 \mathrm{Bi}$ showed the lowest width of flank wear land VB after a number of $n=2,500$ holes. Machining $38 \mathrm{LS}$ and $38 \mathrm{Se}$ resulted in the highest width of flank wear land VB, while drilling $43 \mathrm{LS}$ as well as $43 \mathrm{Bi}$ in longitudinal direction resulted in cutting edge chipping after $n=2,030$ and $n=1,610$ drill holes, respectively.
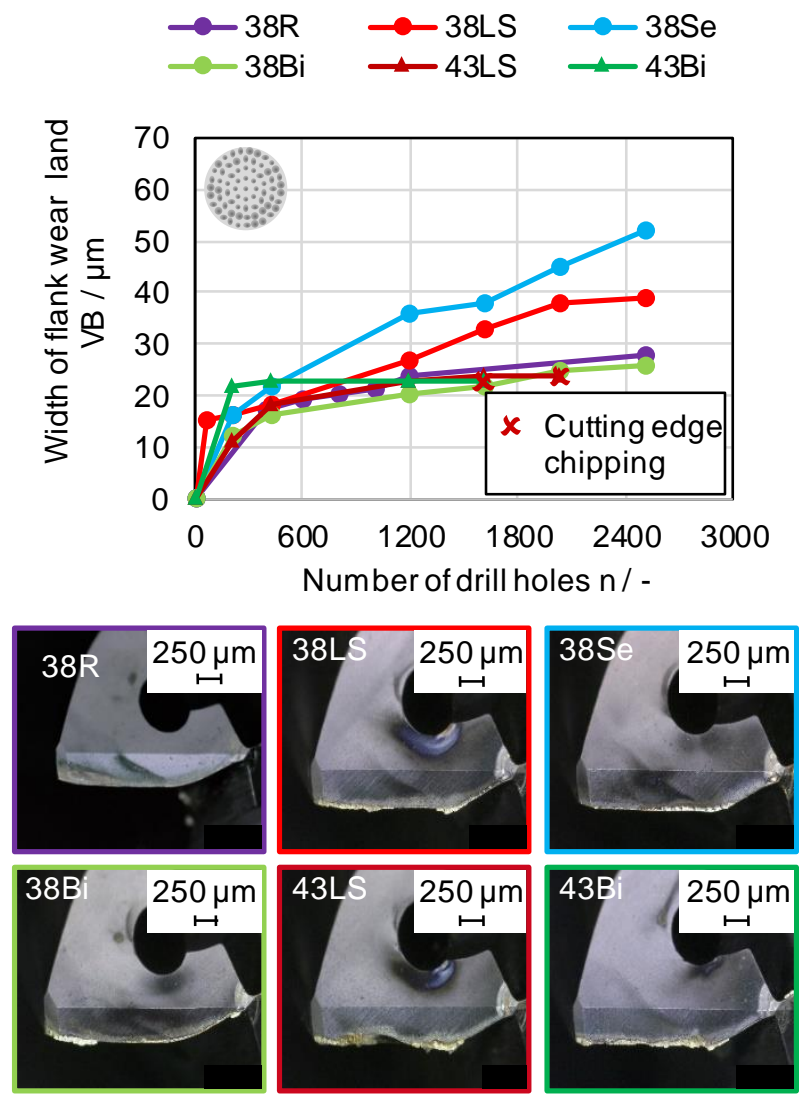

$\begin{array}{llll}\text { Tool supplier: } & \text { Gühring } & \text { Feed rate: } & \mathrm{f}=0.16 \mathrm{~mm} \\ \text { Tool typ: } & \text { RT } 100 \mathrm{U} & \text { Stroke: } & \mathrm{I}_{\mathrm{e}}=15.5 \mathrm{~mm} \\ \text { Coating: } & \text { Nano-FireX } & \text { Cutting speed: } & \mathrm{V}_{\mathrm{c}}=70 \mathrm{~m} / \mathrm{min} \\ \text { Diameter: } & \mathrm{d}=5 \mathrm{~mm} & \text { Lubrication: } & \text { MQL }(\mathrm{c}-\mathrm{st})\end{array}$

Fig. 3: Wear development for longitudinal drilling.

In Fig. 4, the wear development as a function of the number of drill holes is plotted for transversal drilling of the steel variants. The results are similar to the results obtained in longitudinal drilling. Drilling the steel variants $43 \mathrm{LS}$ and $43 \mathrm{Bi}$ resulted in cutting edge chipping after a number of $n=2,030$ and $n=1,600$ drill holes, respectively. Similar to the results from longitudinal drilling, machining the steel variants $38 \mathrm{R}$ and $38 \mathrm{Bi}$ resulted in the lowest width of flank wear land and can be evaluated as the variants with the best performance in drilling.
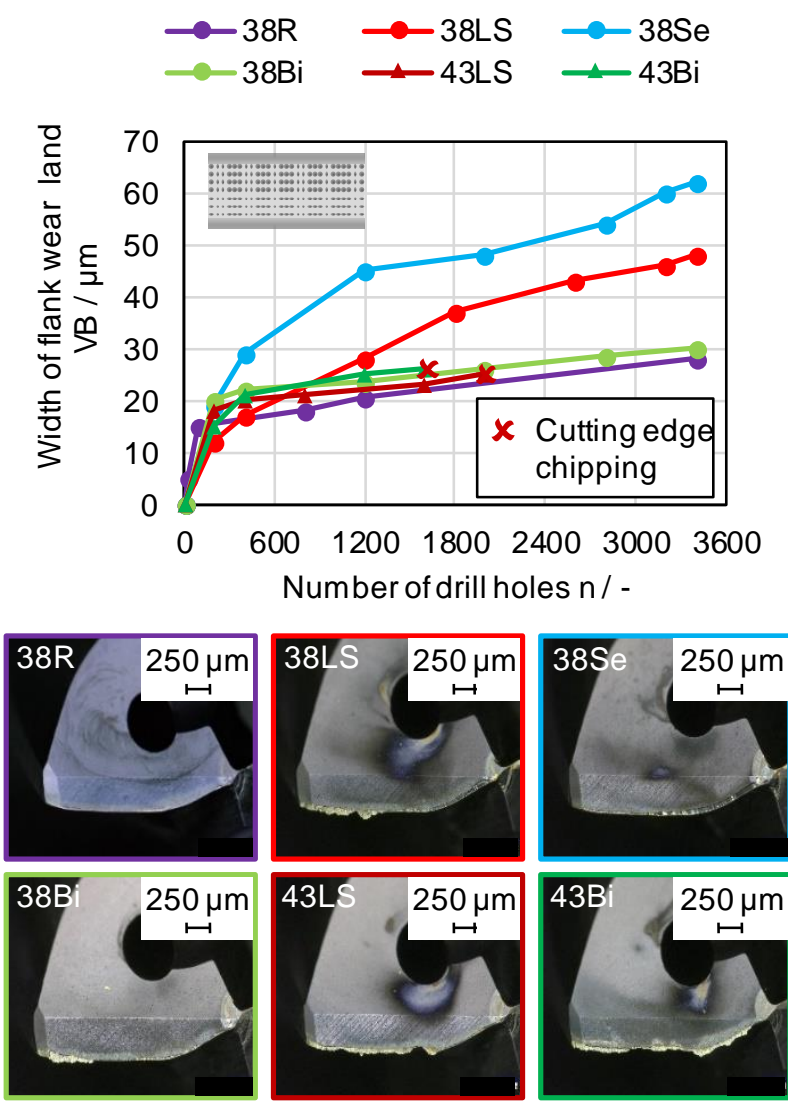

$\begin{array}{llll}\text { Tool supplier: } & \text { Gühring } & \text { Feed rate: } & \mathrm{f}=0.16 \mathrm{~mm} \\ \text { Tool typ: } & \text { RT } 100 \mathrm{U} & \text { Stroke: } & \mathrm{I}_{\mathrm{e}}=15.5 \mathrm{~mm} \\ \text { Coating: } & \text { Nano-FireX } & \text { Cutting speed: } & \mathrm{V}_{\mathrm{c}}=70 \mathrm{~m} / \mathrm{min} \\ \text { Diameter: } & \mathrm{d}=5 \mathrm{~mm} & \text { Lubrication: } & \mathrm{MQL}(\mathrm{c}-\mathrm{st})\end{array}$

Fig. 4: Wear development in transversal drilling.

In comparison to the reference material, the amount of sulfur is lower for $38 \mathrm{Se}$ and $38 \mathrm{Bi}$ (see Tab. 2). The addition of selenium transform the MnS inclusion from an elongated to a globular shape, because of the formation of MnS-Se which are more spherical. The addition of bismuth results in low melting inclusions, which acts as a lubrication film in the cutting zone, reduces the friction and, consequently, results in reduced tool wear in drilling. The differences in longitudinal and transversal drilling is negligible in case of the two additional alloy elements, which can be seen in both 
figures. Overall, the governing wear mechanism were found to be adhesion and abrasion. Adhered material was found in the area of the cutting edge when drilling the stee variants with low sulfur (38LS and $43 \mathrm{LS}$ ) and with $\mathrm{Bi}$ addition (38LS and 43Bi). Wear studies of the cutting too after machining the steel variant 38 Se showed abrasion on the clearance face while no adhered material was obtained.

\subsection{Mechanical Load}

For the transversal drilling tests, the rotating force dynamometer Kistler 9125 was used, because the round workpiece had to be clamped in vice. In longitudinal drilling the workpiece material was clamped in a three-jaw chuck on the static force measurement platform Kistler 9272. In the beginning, test measurements were performed to ensure the comparability between the two measurement setups. Furthermore, the position of the drill hole in relation to the position on the workpiece diameter has to be taken into account. Due to hardness variations between the rim zone and the bulk material $\left(\Delta \mathrm{H}_{\max } \approx 30 \mathrm{HV}\right)$, the measured forces varied when drilling in longitudinal direction. In Fig. 5 , an example of the measured axial force is shown. In order to ensure the comparability for the longitudinal tests, the process forces for the rim zone were always evaluated. Force measurements when machining the rim zone are of higher industrial importance than these in the core. In transversal drilling, the workpiece material was prepared by face milling to ensure an even entry of the tool. Regarding the axial forces, no difference was seen between the different positions of the drill holes (see Fig. 5).
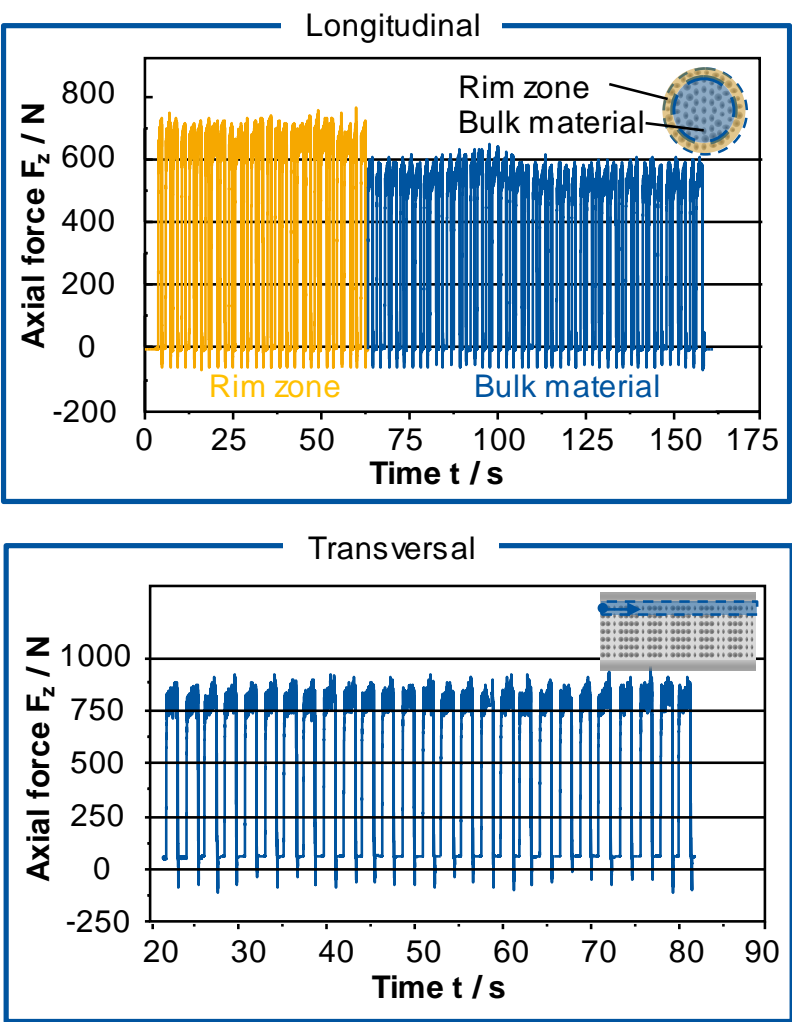

Fig. 5: Cutting force signal when drilling in longitudinal and transversal direction.

For reason of comparison, the average value of the first line of drill holes was always evaluated. Besides the axial force $\mathrm{F}_{\mathrm{z}}$ also the torque $\mathrm{M}_{\mathrm{z}}$ was measured and evaluated. The conclusions drawn from the axial force signal are also transferable to the torque signal.
An analysis of the mechanical load on the cutting tool provides the opportunity to draw conclusions on the machinability of the different steel variants and how the addition of further elements ( $\mathrm{Bi}$ and $\mathrm{Se}$ ) affect the contact conditions in the cutting zone. As described above, the mechanical tool load was measured during the machining tests. A comparison of the process forces between longitudinal and transversal drilling is shown in Fig. 6.

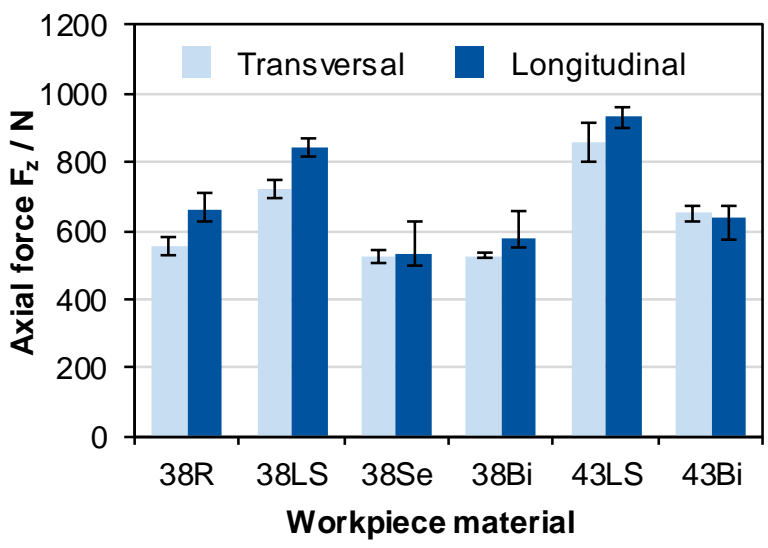

$\begin{array}{llll}\text { Tool supplier: } & \text { Gühring } & \text { Feed rate: } & \mathrm{f}=0.16 \mathrm{~mm} \\ \text { Tool typ: } & \text { RT } 100 \mathrm{U} & \text { Stroke: } & \mathrm{I}_{\mathrm{e}}=15.5 \mathrm{~mm} \\ \text { Coating: } & \text { Nano-FireX } & \text { Cutting speed: } & \mathrm{V}_{\mathrm{c}}=70 \mathrm{~m} / \mathrm{min} \\ \text { Diameter: } & d=5 \mathrm{~mm} & \text { Lubrication: } & \text { MQL (c-st) }\end{array}$

\section{Fig. 6: Comparison of axial force in longitudinal and} transversal direction.

It can be seen, that the related difference between longitudinal and transversal process forces is the highest, when machining 38R. This can be related to the anisotropic behavior of the material due to the elongated MnS inclusions. By adding Se, the MnS inclusions become globular. Consequently, the difference in process force between longitudinal and transversal drilling is very low for $38 \mathrm{Se}(+2 \%)$.

Furthermore, the obtained results can be evaluated regarding a comparison of an increase or a decrease in axial force from the new steel variants to the reference one. The evaluation shown in Fig. 7 depicts the measured axial cutting force in relation to the measured force when machining 38R. The used signals were all taken from the first drill hole to exclude the influence of the wear state on the process forces and the position of the hole in relation to the diameter of the workpiece material.

For the variants of the $38 \mathrm{MnSiV6}$, the process force strongly increased when the $S$ content was reduced (38LS). It was also demonstrated, that the axial force required to drill $38 \mathrm{Se}$ and $38 \mathrm{Bi}$ in both directions, were lower than for 38R. Thus, Se and $\mathrm{Bi}$ additions not only allowed to compensate the machinability deterioration caused by the lower S content, but they also improved the machinability in drilling in comparison to the reference. Globular MnS inclusions improve the machinability in both machining directions. While the axial force in transversal direction is comparable to $38 \mathrm{R}$, the drop in longitudinal force by $19 \%$ is significant. The addition of $\mathrm{Bi}$ results in low melting inclusions, which reduces the friction in the cutting zone, and, consequently, leads to decreasing mechanical loads on the tool.

In case of the $43 \mathrm{MnSiV} 6$ variants, the high hardness and low $S$ content of 43LS provoked, that the axial force was clearly higher than for the reference material. However, for $43 \mathrm{Bi}$, the bismuth addition largely reduced the effective cutting force in comparison to 43LS. In the case of MM Science Journal | 2019 | Special Issue on HSM2019 
longitudinal drilling, even a comparable value to the reference is reached.

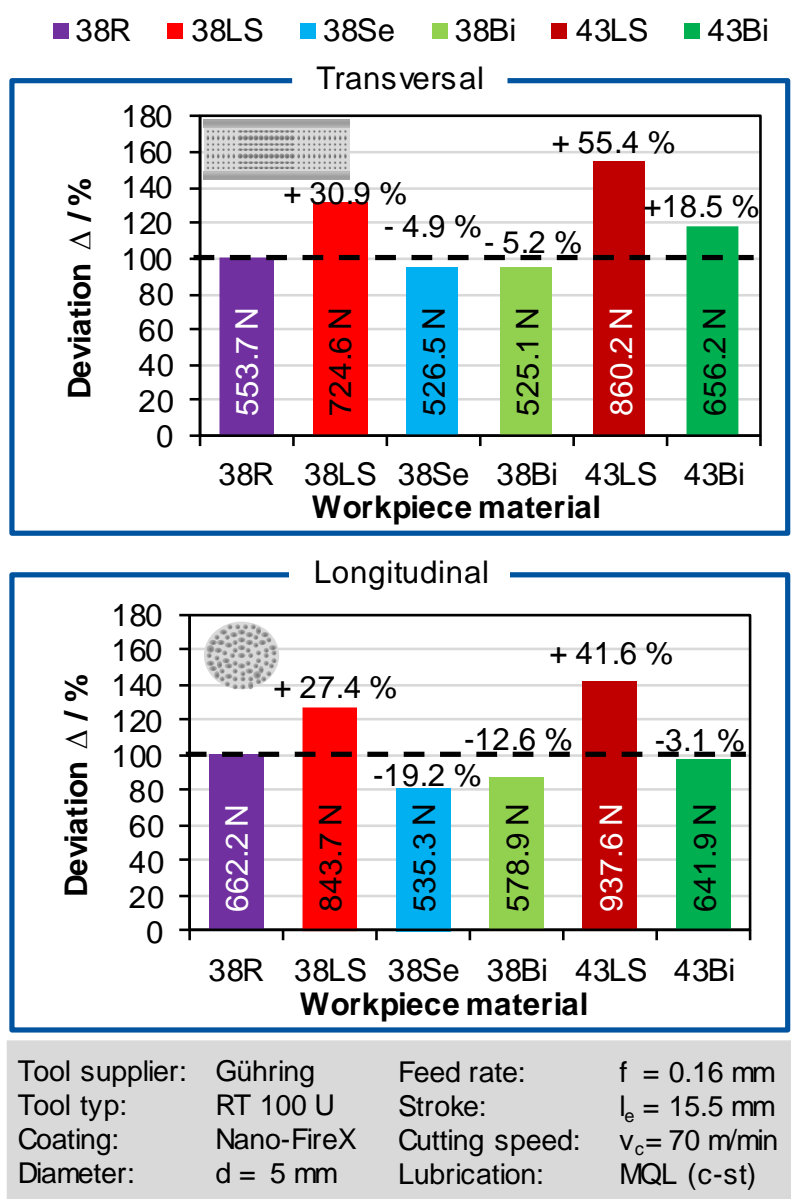

Fig. 7: Relation of measured axial force to $38 R$.

\section{SUMMARY}

The overall aim of this work was to evaluate the influence of different alloy elements on the machinability of microalloyed steel. The purpose was to analyze, if a reduction of the sulfur content and consequently a drop in the machinability due to the MnS reduction can be compensated by adding selenium or bismuth to the steels. Therefore, drilling experiments in longitudinal and transversal direction with regard to the steel fiber were performed and analyzed regarding the width of flank wear land VB and the mechanical load on the cutting tool in terms of the axial force $F_{z}$.

The main conclusions attained from the standard drilling tests are the following ones:

- $\quad 38 \mathrm{Bi}$ was the variant presenting the most similar performance compared to the reference material (38R). In the case of the axial mechanical forces, the force required to drill the variants $38 \mathrm{Se}$ and $38 \mathrm{Bi}$ was even lower than for the reference. This can be related to the alloy elements. While selenium forms globular MnS inclusions as well as manganese selenides, the element bismuth is reducing the friction in the cutting zone due to its low melting point. Those effects lead to a reduction of the cutting force and improve the machinability.

- The steel variant 38LS, due to its lower S content, as well as $38 \mathrm{Se}$ were the variants of the $38 \mathrm{MnSiV} 6$ steel with the fastest increasing width of flank wear land VB in drilling.

- The two 43MnSiV6 variants presented a worse performance than $38 \mathrm{R}$, because of their notably higher hardness and lower $S$ content. In both cases, chipping appeared on the cutting tool, with 43Bi after 1,600 drill holes. When machining 43LS, the tests in both directions were stopped after approx. 2,000 drill holes. The forces required to drill 43Bi were clearly lower than those for drilling 43LS.

\section{ACKNOWLEDGMENTS}

This project has received funding from the Research Fund for Coal and Steel under grant agreement No. 74266. The authors would also like to thank SIDENOR for manufacturing and providing the steel variants used for the investigations.
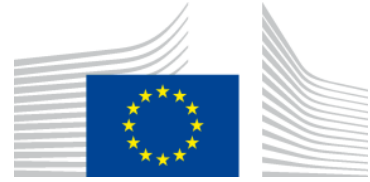

\section{REFERENCES}

[Raedt 2014] Raedt, H.-W. et al. Lightweight forging initiative - Initative Massiver Leichtbau. Steel in Cars and trucks, SCT 2014

[Pawar 2015] Pawar, P. P. et al. Evaluation of crankshaft manufacturing methods - An overview of material removal and additive processes. International Research Journal of Engineering and Technology. Vol. 2 (4), 118-122. 2015

[Montazersadgh 2007] Montazersadgh, F. H. et al. Stress analysis and optimization of crankshafts subject to dynamic loading. Final Project Report submitted to Forging Industry Educational Research Foundation and American Iron and Steel Institute, 2007.

[Pichard 1993] Pichard, C. et al. Altenative materials for the manufacture of automobile components: Example of industrial development of micoralloyed engineering steel for the production of forged crankshafts. Proceedings of the $26^{\text {th }}$ International Symposium on Automotive Technology and Automation. Aachen, Germany, 1993

[Essel 2006] Essel, I. Machnability enhancement of nonleaded free cutting steels. Dissertation, RWTH Aachen, 2006

[ECSC 2004] ECSC 7210-PR/306. Technically and commercially viable alternatives to lead as machinability enhancer in steels used for automotive component manufacture. 2004 